\title{
Fulminant amoebic enteritis that developed in the perinatal period
}

\author{
Mayako Goto, Yasuaki Mizushima, Tetsuya Matsuoka
}

Department of Emergency, Senshu Critical Care Medical Center, Izumisano, Osaka, Japan

\section{Correspondence to} Mayako Goto, mayasan0121@gmail.com

Accepted 4 June 2015
CrossMark

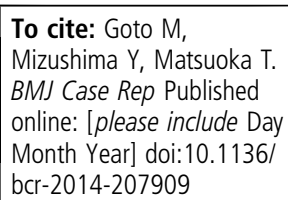

\section{SUMMARY}

We present a case of a 30-year-old postpartum woman who delivered by caesarean section at 34 weeks. On postoperative day 9, she was admitted to our hospital in shock. Emergency abdominal surgery was performed. Massive purulent ascites collected in the abdominal cavity and was associated with intestinal necrosis, which extended from the ascending colon to one-third of the descending colon. The necrotic lesion was excised, and an artificial anus was constructed at the ileum end. A histological finding on the 15th day indicated the possibility of amoebic enteritis, and the patient was started on metronidazole therapy. The diarrhoea improved dramatically after metronidazole treatment was started. The patient was able to walk unassisted on the 45th day and was subsequently discharged. Amoebic enteritis has been thought to be epidemic in developing countries, but today, the incidence of amoebic enteritis as a sexually transmitted disease is increasing in developed countries.

\section{BACKGROUND}

Fulminant amoebic enteritis is a rare condition, comprising only $0.5 \%$ of amoebic enteritis cases, ${ }^{1}$ but presents with perforation and megacolon and has an extremely high case fatality rate of 60 $80 \% .^{2}$ Pregnancy is a risk factor for amoebic enteritis, ${ }^{1}$ but there are few reported cases of fulminant amoebic enteritis in the perinatal period. Here, we report the case of a patient who survived perinatal fulminant amoebic enteritis after delayed diagnosis and treatment.

\section{CASE PRESENTATION}

The patient was a 30-year-old woman (gravida 6 and para 3). She had no anamnesis or record of overseas travel, but was chlamydia-positive during pregnancy.

The patient was hospitalised for bed rest due to a diagnosis of placenta previa at 31 weeks. The baby was delivered by caesarian section at 34 weeks. The operation was performed without transfusion, and vital signs were stable, even though intraoperative bleeding was $1700 \mathrm{~mL}$. On postoperative day 2, the patient had watery diarrhoea with symptoms of infection. On postoperative day 9, she was admitted to our hospital in shock.

\section{INVESTIGATIONS}

\section{Physical examination}

The patient's respiratory rate was $44 / \mathrm{min}$, pulse rate was $130 / \mathrm{min}$, blood pressure was $130 /$ $70 \mathrm{~mm} \mathrm{Hg}$ and blood oxygen levels indicated that ventilation was good. The abdomen showed significant swelling with peritoneal signs. There was massive ascites and a few high-echoic pus-like lesions visualised by abdominal ultrasonography.

\section{Laboratory data}

The white cell count (WCC) count was very low $(900$ cells $/ \mathrm{mm}$ ) and $\mathrm{C}$ reactive protein level was high $(18 \mathrm{mg} / \mathrm{dL})$. The patient also had anaemia and hypoalbuminaemia, but there were no other significant findings (table 1).

\section{Abdominal CT}

The CT showed massive ascites, intestinal expansion and oedema. Free air was identified in the area of the ascending colon and the anterior surface of the uterus (figure 1).

\section{DIFFERENTIAL DIAGNOSIS}

The patient presented with sepsis on admission, and pancytopaenia with coagulopathy was noted. Since it was difficult to define the cause initially, emergency abdominal surgery was performed. The preliminary diagnosis was generalised peritonitis by gastrointestinal perforation or formation of abscesses by gas-producing bacteria.

\begin{tabular}{|c|c|c|c|}
\hline$<\mathrm{CBC}>$ & & $<$ Serology $>$ & \\
\hline WCC & $900 / \mu \mathrm{L}$ & CRP & $18 \mathrm{mg} / \mathrm{dL}$ \\
\hline $\mathrm{RBC}$ & $257 \times 10^{4} / \mu \mathrm{L}$ & $<$ Coaglation $>$ & \\
\hline $\mathrm{Ht}$ & $22 \%$ & PT & $32 \mathrm{~s}$ \\
\hline $\mathrm{Hb}$ & $6.7 \mathrm{~g} / \mathrm{dL}$ & APTT & $14 \mathrm{~s}$ \\
\hline PLT & $20 \times 10^{4} / \mu \mathrm{L}$ & FDP-DD & $4.5 \mu \mathrm{g} / \mathrm{mL}$ \\
\hline \multicolumn{4}{|c|}{$<$ Biochemistry $>$} \\
\hline TP & $3.7 \mathrm{~g} / \mathrm{dL}$ & & \\
\hline Alb & $1.8 \mathrm{~g} / \mathrm{dL}$ & $<$ Artery blood gas & (room air > \\
\hline AST & $6 \mathrm{IU} / \mathrm{I}$ & $\mathrm{pH}$ & 7.53 \\
\hline ALT & $7 \mathrm{IU} / \mathrm{I}$ & $\mathrm{pCO}_{2}$ & $32 \mathrm{~mm} \mathrm{Hg}$ \\
\hline LDH & $228 \mathrm{IU} / \mathrm{I}$ & $\mathrm{pO}_{2}$ & $93 \mathrm{~mm} \mathrm{Hg}$ \\
\hline BUN & $7.4 \mathrm{mg} / \mathrm{dL}$ & $\mathrm{HCO}_{3}-$ & $27 \mathrm{mmol} / \mathrm{L}$ \\
\hline CRE & $0.6 \mathrm{mg} / \mathrm{dL}$ & $\mathrm{BD}$ & $-2.6 \mathrm{mmol} / \mathrm{L}$ \\
\hline $\mathrm{Na}$ & 136 mEq/L & & \\
\hline K & $2.9 \mathrm{mEq} / \mathrm{L}$ & & \\
\hline $\mathrm{Cl}$ & $101 \mathrm{mEq} / \mathrm{L}$ & & \\
\hline
\end{tabular}

ALT, alanine transaminase; APTT, activated partial thromboplastin time; AST, aspartate aminotransferase; BUN, blood urea nitrogen; $C R P, C$ reactive protein; FDP-DD, fibrin degradation products-D-dimer; $\mathrm{Hb}$, haemoglobin; $\mathrm{Ht}$, haematocrit; $\mathrm{LDH}$, lactate dehydrogenase; PLT, platelet; PT, prothrombin time; RBC, red blood cell; WCC, white cell count. 

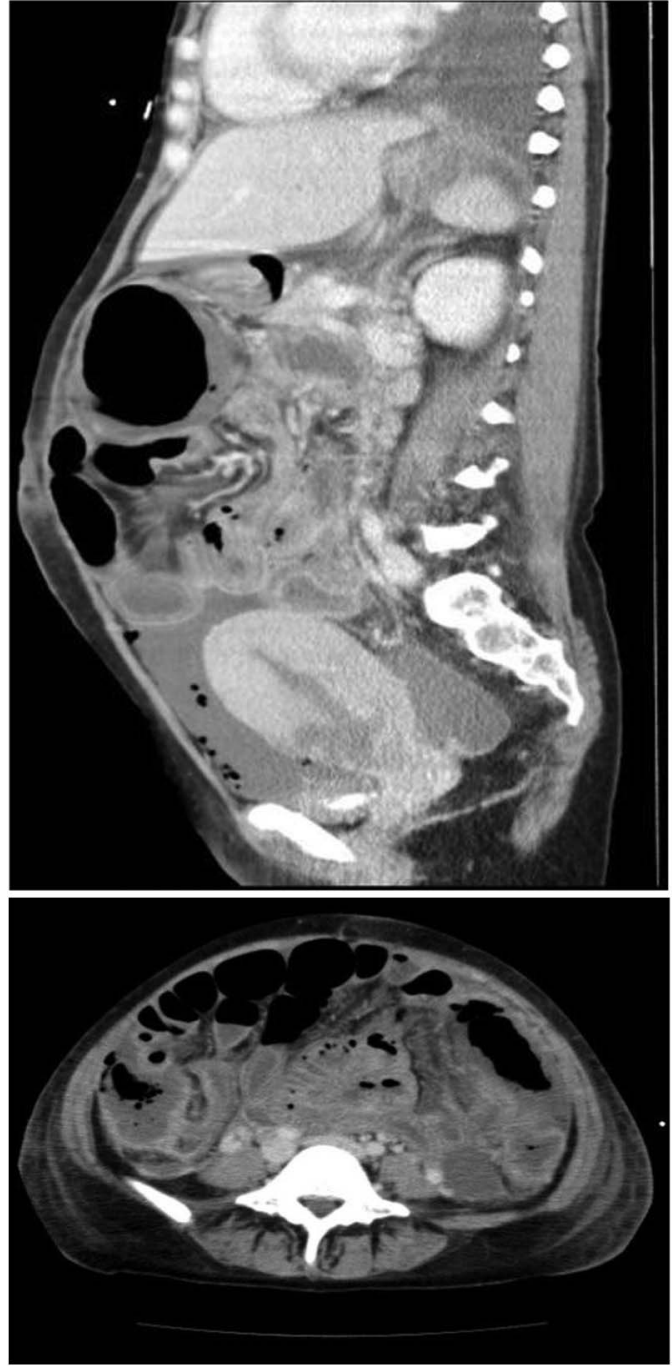

Figure 1 Abdominal $\mathrm{CT}$, initial.

\section{TREATMENT}

\section{First surgery}

Massive purulent ascites collected in the abdominal cavity and was associated with intestinal necrosis, which extended from the ascending colon to one-third of the descending colon. The small intestinal had significant oedema, but good blood flow. The necrotic lesion was excised, and the abdominal cavity was irrigated. A temporary vacuum pack closure was used to allow future access.

\section{Specimen}

From the ascending colon to one-third of the descending colon, there was necrosis throughout, with a geographical false membrane and some perforation (figure 2).

\section{Progress after surgery}

The patient was managed with a temporary closure of the abdomen by vacuum pack from the first to the fourth day after surgery. The abdominal cavity was irrigated every day, but necrosis progressed. Parts of the intestinal tract were removed surgically every day due to perforation, resulting in a descending colon stump and a jejunoileal stump. An artificial anus was constructed at the ileum end on the fourth day. More than $5000 \mathrm{~mL}$ of watery diarrhoea was collected per day after the construction of the artificial anus.

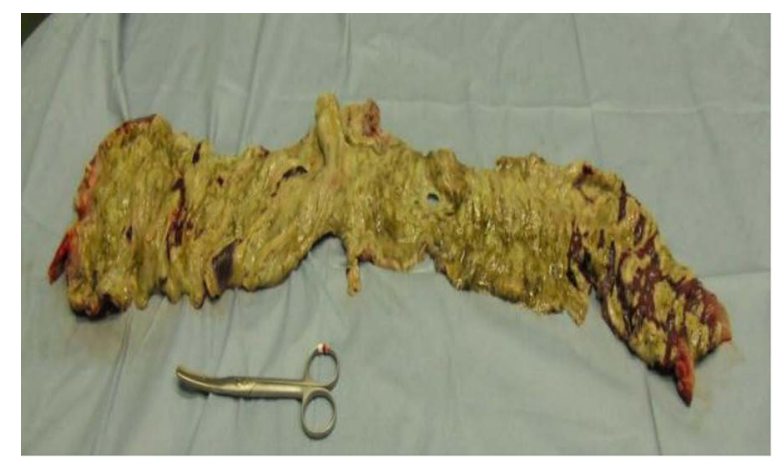

Figure 2 Surgical specimen.

Possible causes of the diarrhoea, including inflammatory bowel disease, were thoroughly investigated. A histological finding on the 15th day indicated the possibility of amoebic enteritis, and the patient was started on metronidazole therapy $(1500 \mathrm{mg} /$ day for 10 days). The diarrhoea improved dramatically after metronidazole treatment was started.

\section{Diagnosis}

The serum amoebic antibody titre was 100 , which was considered a weak positive result (normal value, $<100$ ); serum trophozoites were absent. Pathological examination showed that tissue sections of necrotic tissue were positive by periodic acid-Schiff staining and H\&E staining for innumerable amoebae (trophozoites; figure 3). On the basis of these results, fulminant amoebic enteritis was diagnosed.

\section{OUTCOME AND FOLLOW-UP}

The patient was able to walk unassisted on the 45th day and was subsequently discharged.

\section{DISCUSSION}

Amoebic enteritis is a form of amoebiasis common in people travelling to developing countries. ${ }^{13}$ The incidence of amoebic enteritis has been increasing in Japan since the 1980s and has doubled from 2001 (377 cases) to 2007 (747 cases) ${ }^{3}$ (figure 4). It was thought that polluted food and water in the overseas endemic areas were the primary source of infection, but person-to-person contact was the cause in the majority of the cases, and amoebic enteritis is a sexually transmitted disease. ${ }^{13}$ The ratio of affected men to women is $4: 1$, and male homosexuals are a high-risk group. ${ }^{3}$ Lately, the number of women

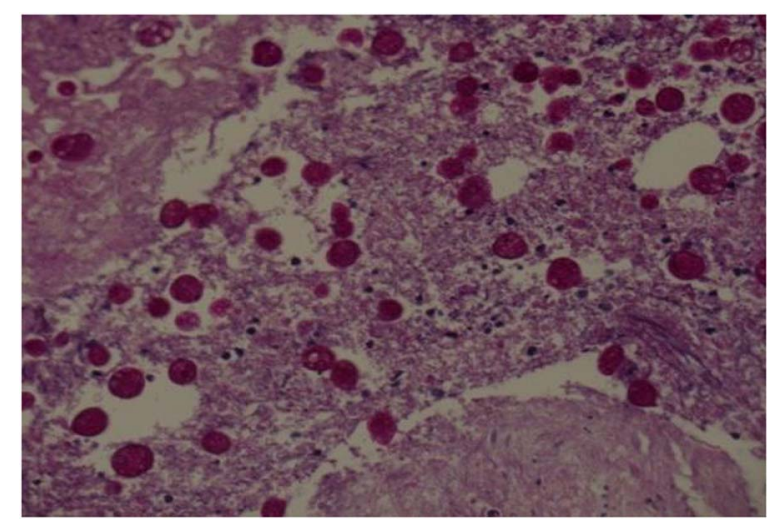

Figure 3 Pathology tissue. 


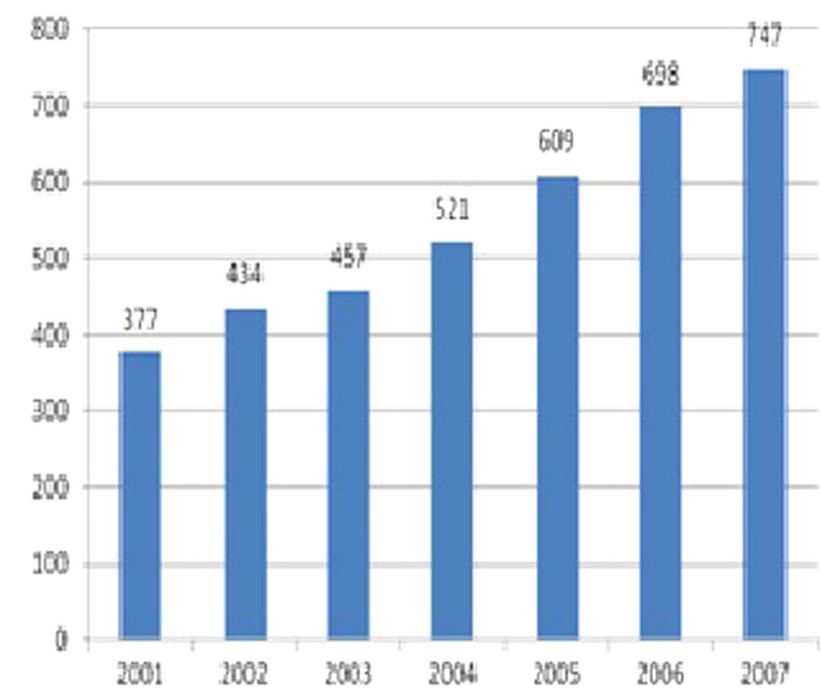

Figure 4 The number of cases of amoebic dysentery per year in Japan (The National Institute of Infectious Diseases, 2001-2007).

contracting the disease is increasing, and there is concern for further spread of amoebic enteritis through heterosexual encounters. ${ }^{3}$ Infection depends on the ingestion of amoeba (Entamoeba histolytica) cysts excreted in the faeces of infected individuals. ${ }^{1}$ Amoebic dysentery develops by excystation of the trophozoites in the small intestine, where they find nourishment for growth, followed by invasion of the intestinal mucosa. ${ }^{1}$ Approximately $10 \%$ of affected patients develop an infection, and the remaining become carriers of latent cysts. ${ }^{1}$

Amoebic enteritis most often follows the assumed course, and mucous and bloody diarrhoea is the main symptom. ${ }^{1} 3$ However, the condition progresses to include gastrointestinal perforation, peritonitis, sepsis and toxic megacolon, as a fulminant model, in only a minimal number of cases. ${ }^{1}$ The frequency of the fulminant forms of amoebic enteritis is considered to be approximately $0.5 \% .^{1}$ However, it is reported that the case fatality rate is more than $60-80 \% .^{2}$ Risk factors for the emergence of the fulminant form include pregnancy, steroid use, cancer and hypoalimentation, which are immune-compromised conditions. ${ }^{1} 45$

Our patient had neither a history of amoebic enteritis nor a record of overseas travel and was hospitalised with total placenta previa for 3 weeks prior to disease onset. Pregnancy is a condition of relatively impaired cell-mediated immunity, caused by the production of progesterone and prostaglandin E2 (PGE2). ${ }^{67}$ Impaired cell-mediated immunity increases the risk of amoebic dysentery, and the triggers for fulminant disease in this case were thought to be the pregnancy and the caesarean section with massive haemorrhage. The patient was in a state of impaired cell-mediated immunity induced by pregnancy-related progesterone increase and PGE2 production; the invasive surgery then led to a further decrease in cell-mediated immunity due to loss of WCCs and hypercytokinaemia (of PGE2 and interleukin-10).

Fulminant amoebic enteritis has a poor prognosis and often requires the patient to undergo extensive enterectomy; ${ }^{2} 48$ however, metronidazole is an effective treatment. ${ }^{19}$ By considering amoebic enteritis at the onset of symptoms and diagnosing it at an early stage, we can treat patients with metronidazole therapy.
In this case, the administration of metronidazole was delayed because we did not consider amoebic enteritis as a differential diagnosis. Although pregnancy is considered a risk factor for amoebic enteritis, there have been only five reported cases of perinatal amoebic enteritis. ${ }^{10-14}$ In 1979, in Tanzania, $15 \%$ of perinatal deaths were caused by enteritis, and it is possible that amoebic enteritis was involved. ${ }^{15}$

Amoebic enteritis has been thought to be epidemic in developing countries, but today, the incidence of amoebic enteritis as a sexually transmitted disease is increasing in developed countries. Therefore, we must consider amoebic enteritis in the differential diagnoses for intractable diarrhoea with bloody stools in the perinatal period for women in Japan.

\section{Learning points}

- Fulminant amoebic enteritis is a rare condition, comprising only $0.5 \%$ of amoebic enteritis cases, but presents with perforation and megacolon and has an extremely high-case fatality rate of $60-80 \%$.

- Pregnancy is a risk factor for amoebic enteritis, but there are few reported cases of fulminant amoebic enteritis in the perinatal period.

- Fulminant amoebic enteritis has a poor prognosis and often requires the patient to undergo extensive enterectomy; however, metronidazole is an effective treatment.

- Amoebic enteritis has been thought to be epidemic in developing countries, but today, the incidence of amoebic enteritis as a sexually transmitted disease is increasing in developed countries.

Competing interests None declared.

Patient consent Obtained.

Provenance and peer review Not commissioned; externally peer reviewed.

\section{REFERENCES}

1 Samuel SL Jr. Amoebiasis. Lancet 2003;361:1025-34.

2 Aristizabal H, Acebedo J, Botero M. Fluminant amebic colitis. World J Surg 1991;15:216-25.

3 National Institute of Infectious Diseases. Amoebiasis. Infect Dis Wkly Rep Japan 2008; 10:13-20.

4 Takahashi T, Gamboa-Dominguez A, Gomez-Mendez TJ, et al. Fulminant amebic colitis: analysis of 55 cases. Dis Colon Rectum 1997;40:1362-7.

5 Cardoso JM, Kimura K, Stoopen M, et al. Radiology of invasive amebiasis of the colon. Am J Roentgenol 1977;128:935-41.

6 Weinberg ED. Pregnancy-associated immune suppression: risks and mechanisms. Microb Pathog 1987;3:393.

7 Mattiesen L, Berg G, Ernerudh J, et al. Lymphocyte subsets and mitogen stimulation of blood lymphocytes in normal pregnancy. Am J Reprod Immunol 1996;35:70.

8 Ellyson JH, Bezmalinovic Z, Parks SN, et al. Necrotizing amebic colitis: a frequently fatal complication. Am J Surg 1986;152:21-6.

9 Kimura M, Nakamura T, Nawa Y. Experience with intraverous metronidazole to treat moderate-to-severe amebiasis in Japan. Am J Trop Med Hyg 2007;77:381-5.

10 Wig JD, Bushnurmath SR, Kaushik SP. Complication of amoebiasis in pregnancy and puerperium. Indian J Gastroenterol 1984;3:37-8.

11 Armon PJ. Amoebiasis in pregnancy and the puerperium. Br J Obstet Gynaecol 1978;85:264-9.

12 Kerrigan KR. Fuluminant amoebic colitis in pregnancy. Trop Doct 1991;21:46-7.

13 Bourderix 0, Andreu JM, Sartelet H, et al. Post-partum malignant amebic colitis. Apropos of a case. Ann Chir 1996;50:566-9.

14 Taurelle $R$, Masquet P. Paracute malignant colonic amebiasis and pregnancy. A resent case. J Gynecol Biol Reprod(Paris) 1973;2:433-40.

15 Armon PJ. Maternal deaths in the Kilimanjaro region of Tanzania. Trans $R$ Soc Trop Med Hyg 1979;73:284-8. 
Copyright 2015 BMJ Publishing Group. All rights reserved. For permission to reuse any of this content visit http://group.bmj.com/group/rights-licensing/permissions.

BMJ Case Report Fellows may re-use this article for personal use and teaching without any further permission.

Become a Fellow of BMJ Case Reports today and you can:

- Submit as many cases as you like

- Enjoy fast sympathetic peer review and rapid publication of accepted articles

- Access all the published articles

- Re-use any of the published material for personal use and teaching without further permission

For information on Institutional Fellowships contact consortiasales@bmjgroup.com

Visit casereports.bmj.com for more articles like this and to become a Fellow 